\title{
Surgical Management of Egg Bound in a Gramasree Chicken- A Case Report
}

\author{
B. M. Nijin Jos* \\ Kerala Animal Husbandry Department, Veterinary Surgeon, District Veterinary Centre, \\ Kollam, India \\ *Corresponding author
}

\section{A B S T R A C T}

\begin{tabular}{|l|}
\hline Ke y w o r d s \\
Poultry, Egg \\
$\begin{array}{l}\text { Bound, } \\
\text { Laparotomy, } \\
\text { Radiograpjic } \\
\text { examination }\end{array}$ \\
\hline Article Info \\
\hline $\begin{array}{l}\text { Accepted: } \\
\text { 22 June 2020 } \\
\text { Available Online: } \\
\text { 10 July 2020 }\end{array}$ \\
\hline
\end{tabular}

\section{Introduction}

Backyard system of rearing poultry has contributed a major share in maintaining the sole purpose of providing food and nutritional security of the country. It plays a major role in rural economy and women empowerment (Sheik et al., 2018). Gramasree breed of birds are more commonly used for this purpose in the State of Kerala.

The backyard rearing rarely causes any type of medical emergencies in such birds. Egg bound, a condition often seen in young birds which have started laying wherein the eggs gets lodged in the vent region and difficulty is felt in laying them (Crespo and Shivaprasad, 2003).

A six months old gramasree bird presented with difficulty in laying egg was presented.

On physical and radiographical examination the condition was diagnosed as egg bound. One of the egg that was strangulated was carefully removed manually after proper lubrication and physical manipulation, the second egg that was found in the uterus was removed by laparotomy. 


\section{Materials and Methods}

\section{Anamnesis and diagnosis}

A six months old gramasree bird was presented with the complaint that the bird is unable to lay egg and part of an egg is seen to protruding through the vent region.

On examination the bird was found to be weak and inactive. On physical examination an egg could be palpated in the vent region. Radiographic examination revealed the presence of two eggs one was closer to the vent and the other was found deeper in the uterus.

\section{Surgical procedure}

The vent region and the caudal mid ventral sites were prepared for aseptic surgery. The bird was anesthetized with xylazine hydrochloride at the rate of $2 \mathrm{mg}$ per kilogram body weight intramuscularly and ketamine hydrochloride at the dose rate of $10 \mathrm{mg}$ per kilogram body weight intramuscularly. The egg that was lodged in the vent region was carefully removed after proper lubrication. A caudal mid ventral laparotomy was done and care taken not to injure the cadual air sac. The egg that was found lodged in the uterus was carefully removed after incising the thin walls of the uterus. The wound edges of the uterus were closed in a simple continuous fashion with a 3-0 polyglycolic acid suture. And thereafter the muscle and skin was apposed in the routine manner. Post operatively the bird was maintained on antibiotics and supportive therapy for five days.

\section{Results and Discussion}

The six months old gramasree chicken that was presented with egg bound recovered uneventfully following manual removal of one egg and the second egg removed after laparotomy. The bird was kept on post operative antibiotics and supportive therapy and was advised to keep in a dark environment and controlled feeding.

\section{Acknowledgement}

The author would like to thank Director, Kerala Animal Husbandry Department, District Animal Husbandry Officer, Kollam and Chief Veterinary Officer, District Veterinary Centre Kollam for providing the facilities for the successful completion of the work.

Fig.1 Radiograph showing the presence of two eggs

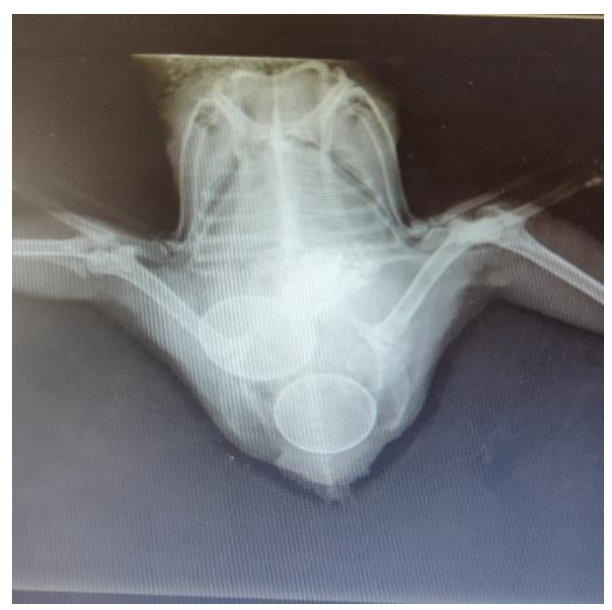


Fig.2 Bird after surgery

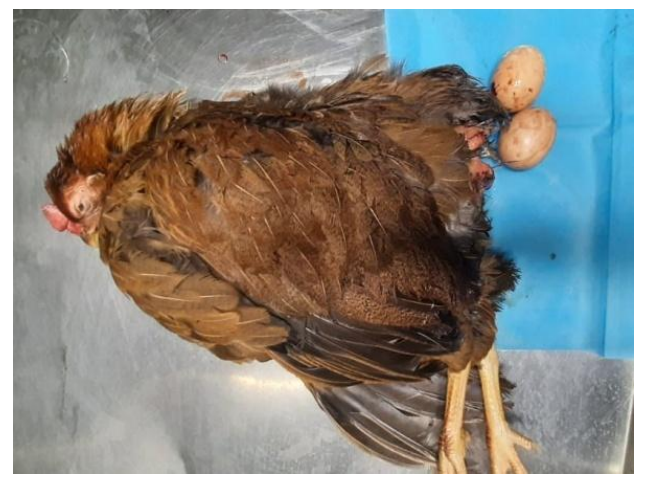

Egg bound is a condition that is seen in birds that occur following the lodgement of egg in the cloaca and failure in laying it (Crespo and Shivaprasad, 2003). The etiology for this condition is numerous. According to Harrisson (2006) salpingitis, atony or paralysis of the oviduct are the main causes for the occurrence of egg bound in birds. Large sized egg can be another causative reason for the development of this condition (Crespo and Shivaprasad, 2003). Srinivasan et al., 2014 reported that heat stress, asphyxia, hypocalcaemia, salpingitis, large-sized egg, dehydration, vent trauma, obesity, abnormal ovulation and oviduct neoplasm can be the causative factors that can lead to egg bound in laying birds.

Manual removal of the egg after proper lubrication and careful physical manipulation can resolve the condition (Joy and Divya., 2014). But in this case there were two eggs and the second one was located in the uterus which could not be removed by physical manipulation. Hence an emergency laparotomy was done. Following surgery the bird was kept in a dark room for 7 days and with controlled feeding. As light is very much necessary for the production of the egg (Jacome et al., 2014), the dark environment was created to reduce the chance of production of another egg that may hinder with the healing of the uterus and thus may become fatal to the life of the bird.

\section{References}

Crespo, R and Shivprasad, H. L. 2003. Developmental, metabolic and other noninfectious disorders. In: Saif YM, (Ed.). Diseases of Poultry, 11th Edn. USA: Iowa State Press, Blackwell Publishers; 1231.

Harrison, G. J.1986. Reproductive medicine. In: Harrison GJ, Harrison LR (Eds.). Clinical Avian Medicine and Surgery. Philadelphia: WB Saunders; 620-623.

Jacome, I.M.T.D. Rossi, L.A. and Borille, R. 2014. Influence of artificial lighting on the performance and egg quality of commercial layers: a review. Rev. Bras. Cienc. Avic. 16(4)

Joy, B and Divya, T. R. 2014. Egg bound and vent prolapse in chicken - a review of two cases. Bangl. J. Vet. Med. 12 (1): 91-92.

Sheikh,I.U., Nissa, S.S., Zaffer, B., Akand, A.H., Bulbul, K.H., Hasin, D., hussain, I. and Hussain, S.A.2018.Propagation of backyard poultry farming for nutritional security in rural areas. Int. J. Vet. Scien. Anim. Husbandry. 3(4):03-06.

Srinivasan, P. Balasubramaniam, G.A. Murthy T.R.G.K. and Balachandran, P. 2014. Prevalence and Pathology of Egg Bound Syndrome in Commercial White Leghorn Chicken. J. World's Poult. Res. 4(2): 30-36. 


\section{How to cite this article:}

Nijin Jos, B .M. 2020. Surgical Management of Egg Bound in a Gramasree Chicken- A Case Report. Int.J.Curr.Microbiol.App.Sci. 9(07): 3642-3645.

doi: https://doi.org/10.20546/ijcmas.2020.907.425 